\title{
Research of Gamma Radiation Impact on Motor Fuels from Azerbaijan Oil
}

\author{
Lala Jabbarova \\ Institute of Radiation Problems, National Academy of Sciences of Azerbaijan, Baku, Azerbaijan
}

Email address:

clala@mail.ru

\section{To cite this article:}

Lala Jabbarova. Research of Gamma Radiation Impact on Motor Fuels from Azerbaijan Oil. Radiation Science and Technology. Vol. 6, No. 1, 2020, pp. 1-6. doi: 10.11648/j.rst.20200601.11

Received: September 3, 2020; Accepted: January 28, 2020; Published: April 8, 2020

\begin{abstract}
In connection with the opportunity to develop new technological processes with the use of radioactive energy, it is necessary to study the effect of various types of radiation on hydrocarbons and oil products. The process of radiolysis is complex and diverse. The conversion mechanism of fuel hydrocarbons is still studied by not enough. These changes can vary widely - from the changes in individual working properties of fuel to its complete destruction. At the same time, practice requires testing materials for radiation resistance in order to determine the limits of their applicability and the possibility to use radiation as a technological factor for improving the properties of materials. As the object of study used samples of gasolines fuels AI-92, AI-95 and diesel fuel. Laboratory researches were conducted on gamma source Co60 at the power of dose of $\mathrm{P}=0.18 \mathrm{~Gy} / \mathrm{s}$, at the room temperature and at various absorbed doses $\mathrm{D}=15-150 \mathrm{KGy}$. Investigated impact of radiation on operational characteristics of fuels is in static conditions before and after irradiation. Results of such researches allow estimating radiation stability of fuels, to find out influence of radiation on the general composition of fuels and possible changes of fuels qualities.
\end{abstract}

Keywords: Gasoline Fuel, Diesel Fuel, Radiolysis

\section{Introduction}

Automobile and aviation gasolines fuels must meet the requirements of operation - have good evaporability at any temperatures. Must have a hydrocarbon composition that provides in the conditions of radiation without a detonation of the combustion process in all engine operating modes. The amount of decomposed hydrocarbon increases with increasing absorbed radiation dose. The chemical stability of the fuels determined by the presence of unsaturated hydrocarbons is in the fuel. They are thermally unstable and lead to the formation of tar and deposits in the engine intake system. Their evaporation into the atmosphere contributes to the formation of ozone, and their combustion products form toxic dienes. In a stationary power reactor, in nuclear power plants of vehicles such as underwater and surface vessels, optimal protection can be provided, so for lubricants or liquids, the problem of radiation resistance arises only when they are near the radiation source. The methods used to determine radiation stability are based on the irradiation of the product and the subsequent determination of the changes that have occurred therein. It is known that the main cause of low stability is the presence of unsaturated compounds in the fuel. Influence of radiation on oil fuels was previously presented in works [1-12]. Also, the results of experimental studies of the radiation-chemical transformation of synthetic oil from petroleum bituminous rock and oil fractions were cited $[13,14]$. The purpose of this work is to study the effect of radiation on certain technical characteristics of gasoline and diesel fuel.

\section{Methodology}

The samples (fuels on $100 \mathrm{ml}$ ), were irradiated at room temperature on gamma-source $\mathrm{Co}^{60}$ at dose rate $\mathrm{P}=0.18 \mathrm{~Gy} / \mathrm{h}$ at different absorption doses: within the range of 15-150 kGy in vacuum so as to trace the kinetics of the current processes. As an ionizing radiation it was used Y-radiation source $\mathrm{Co}^{60}$ of type MPX Y-30. Gas products were analyzed by gas chromatography method. The density was determined by a pycnometer according to GOST 3900-85. The viscosity was 
determined according to GOST 33-66 by a viscometer of VPJ-2 type corresponding to GOST 10028-81. The aim of the work is the study of radiation resistance of fuel were determined before and after irradiation at various absorbed dos. Octane and cetane numbers and other characteristics of fuels before and after irradiation were determined by Zeltex ZX-440 XL (ZX-440XL - Near Infected Gasoline/Diesel Fuel Analyzer es.

\section{Experiments and Results}

Structuring physically manifests itself in liquids in changes in viscosity and density. The density indirectly characterizes the chemical properties of the fuel, fractional composition and vaporability. The density of the starting gasoline AI-92 $0.725 \mathrm{~g} / \mathrm{cm}^{3}$. The following Figure $1(\mathrm{a}, \mathrm{b})$ shows changes in viscosity and density of gasoline before and after radiation at different absorbed doses immediately after irradiation.
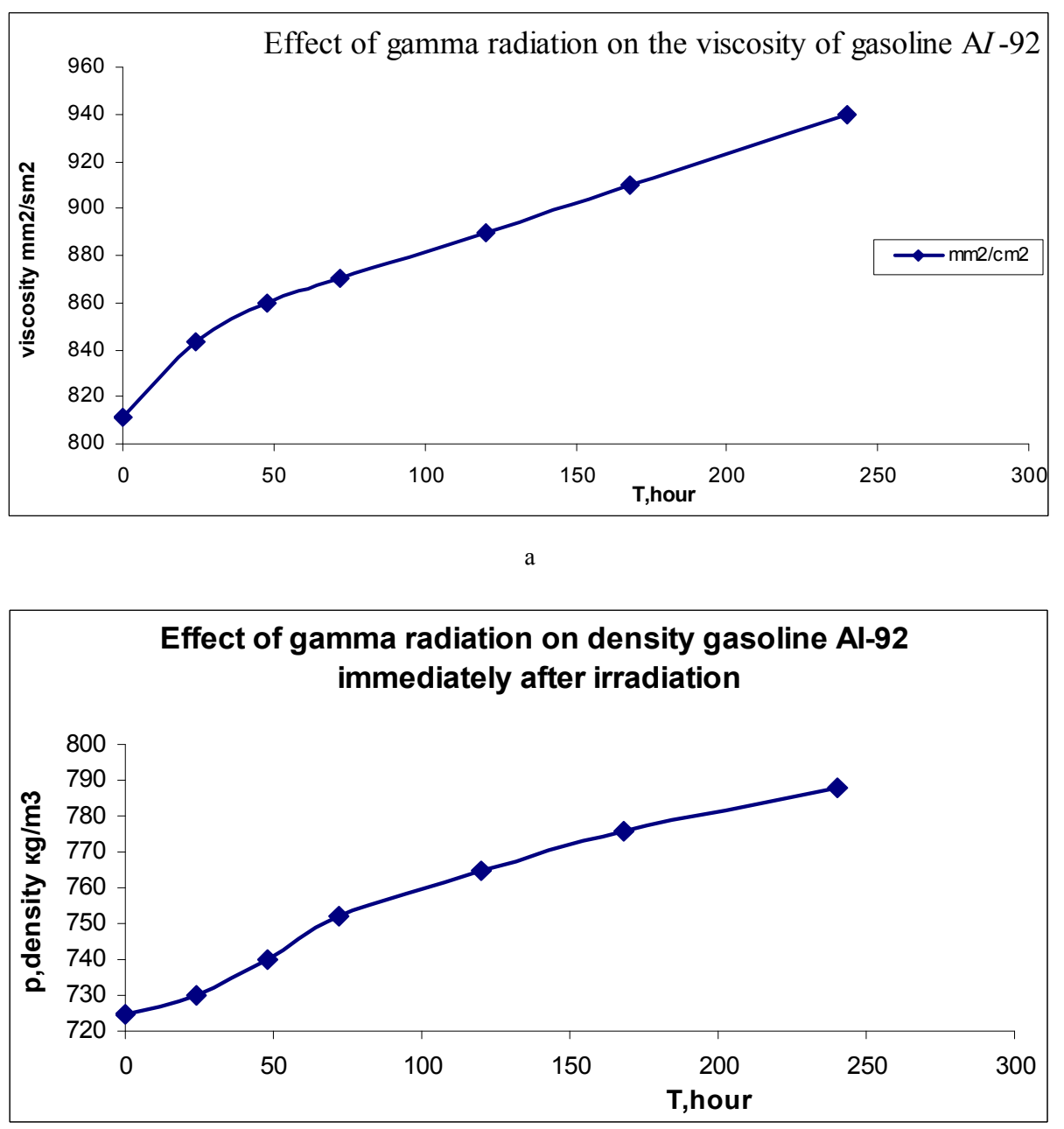

b

Figure 1. (a, b) Changes viscosity and density of gasoline before and after radiation at different absorbed doses.

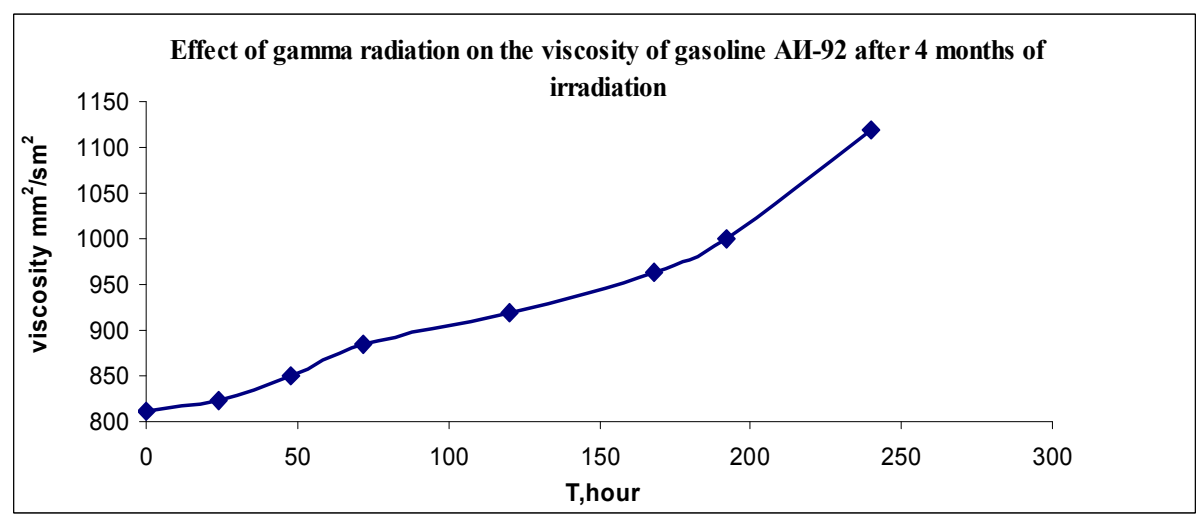




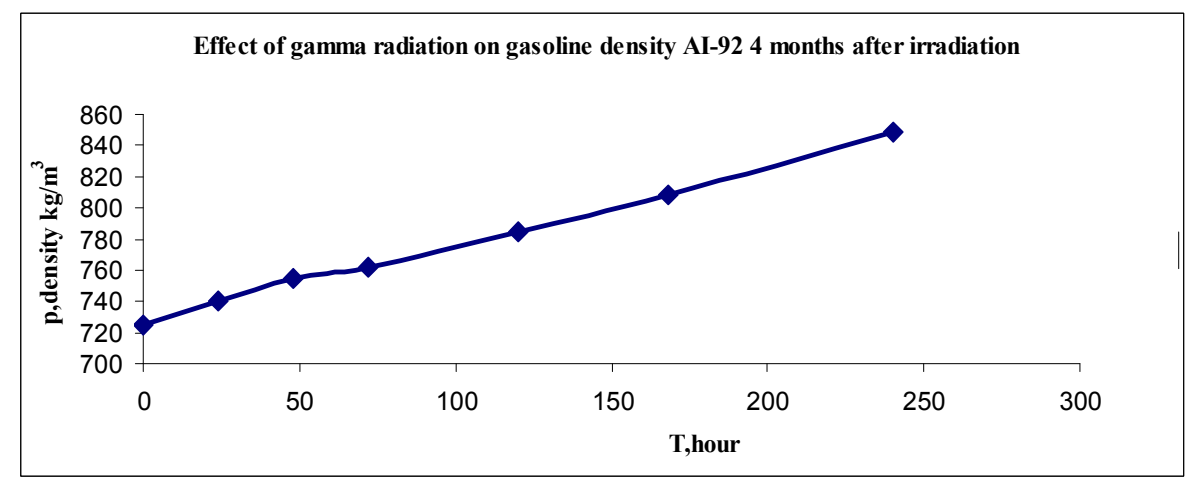

b

Figure 2. (a, b). Change in viscosity and density of gasoline AИ-92 after 4 months of irradiation at different absorbed doses.
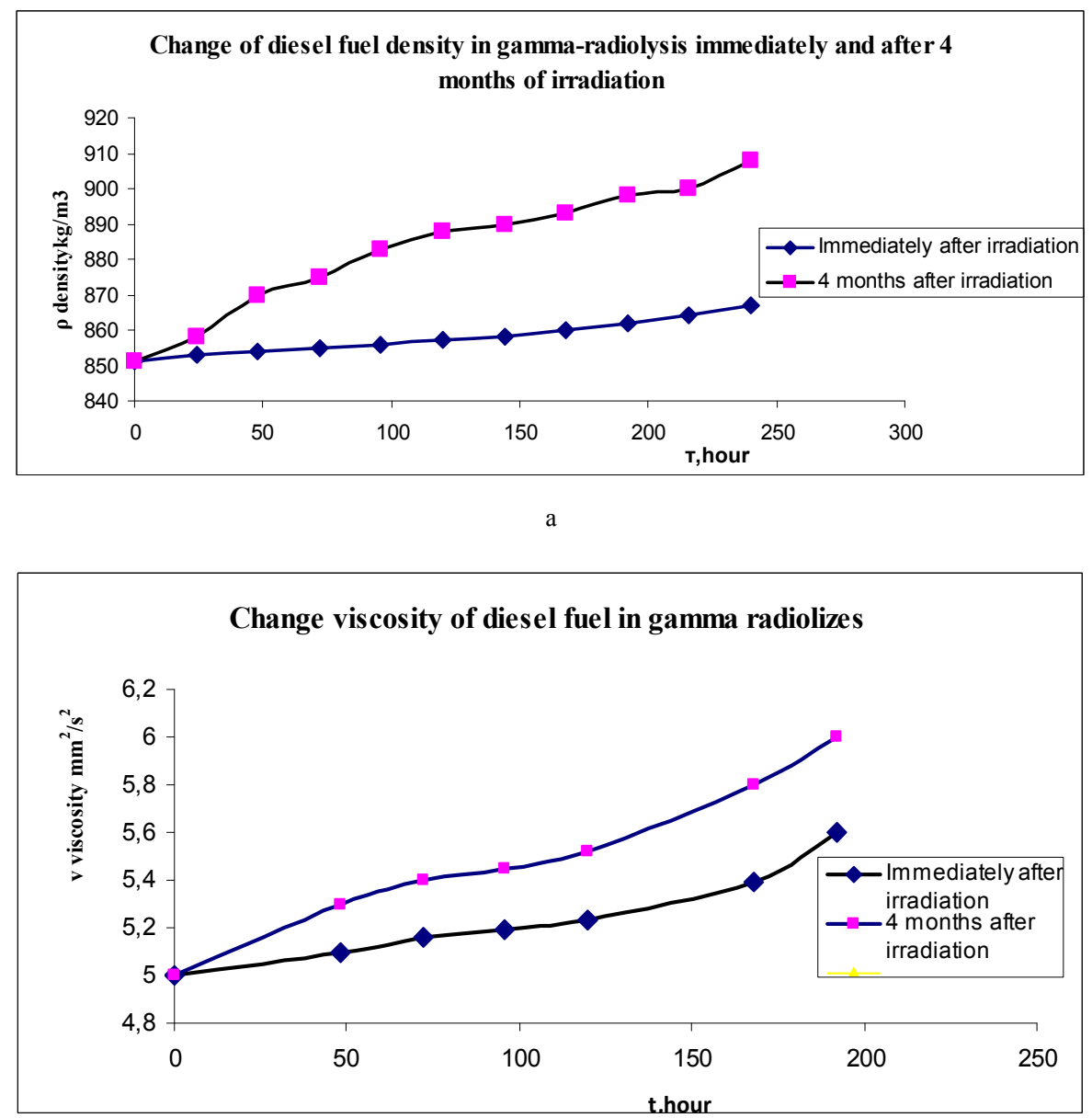

b

Figure 3. (a, b). Change in viscosity and density of diesel fuel immediately after irradiation and 4 months after irradiation at different absorbed doses.

Technical characteristics of Gasoline AI-95 before and after gamma radiation are given below table 1 and table 2 .

Table 1. Analysis data of gasoline AI -95 starting gasoline on ZX-440 XL apparatus.

\begin{tabular}{ll}
\hline Analysis data of gasoline $\mathbf{A I} \mathbf{- 9 5}$ starting gasoline on $\mathbf{Z X - 4 4 0 ~ X L}$ apparatus. Temperature $\mathbf{2 0} \mathbf{C}^{\circ} \mathbf{.}$ \\
\hline Density $15^{\circ} \mathrm{C}$ & $761,5 \mathrm{~kg} / \mathrm{m} 3$ \\
ETBE & 0,46 \\
Ethanol & 0,8 \\
TAME & 1,5 \\
IBR & 35,5 \\
RON South Africa & 95,3 \\
\hline
\end{tabular}




\begin{tabular}{lc}
\hline Analysis data of gasoline $\mathbf{A I} \mathbf{- 9 5}$ starting gasoline on $\mathbf{Z X - 4 4 0 ~} \mathbf{X L}$ apparatus. Temperature $\mathbf{2 0} \mathbf{~} \mathbf{C}^{\circ}$ \\
\hline Total aromatics & 38,6 \\
Benzene & 0,58 \\
Total oxygen & 1,4 \\
Total olefines & 9,6 \\
MON & 84 \\
IBP & 35,3 \\
T 10 & 56,2 \\
T 50 & 100,2 \\
T 90 & 165,2 \\
\hline
\end{tabular}

Below shows an analysis of irradiated AI-95 gasoline at an absorbed dose of D=78 kGy on an ZX-440 XL apparatus.

Table 2. Analysis data of gasoline AI -95 after gamma radiation On ZX-440 apparatus XL. Absorbed dose D=78 kGy.

\begin{tabular}{ll}
\hline The analysis data of Gasoline AI-95 after gamma radiation on $\mathbf{Z X - 4 4 0}$ apparatus XL. Absorbed dose of $\mathbf{D}=\mathbf{7 8} \mathbf{~ k G y}$. Temperature $\mathbf{2 0}{ }^{\circ} \mathbf{C}$. \\
\hline Density $15^{\circ} \mathrm{C}$ & $759,70 \mathrm{~kg} / \mathrm{m} 3$ \\
ETBE & 0,23 \\
Ethanol & 0,8 \\
TAME & 1,6 \\
IBR & 35,7 \\
RON South Africa & 95,2 \\
Total aromatics & 38,8 \\
Benzene & 0,59 \\
Total oxygen & 1,4 \\
Total olefines & 9,5 \\
MON & 84 \\
IBP & 35,2 \\
T 10 & 57,5 \\
T 50 & 100,7 \\
T 90 & 164,5 \\
\hline
\end{tabular}

Table 3. Analysis data of gasoline AI -95 after gamma radiation on ZX-440 apparatus XL after 4 months storage. Absorbed dose D=53kGy.

\begin{tabular}{|c|c|}
\hline \multicolumn{2}{|c|}{$\begin{array}{l}\text { The analysis data on the apparatus } \mathrm{ZX}-440 \mathrm{XL} \text { irradiated gasoline } \mathrm{A} I-95 \text { at the absorbed dose } \mathrm{D}=53 \mathrm{kGy} \text { after } 4 \text { months storage. Temperature } \\
20^{\circ} \mathrm{C} \text {. }\end{array}$} \\
\hline Density $15^{\circ} \mathrm{C}$ & $847,90 \mathrm{~kg} / \mathrm{m} 3$ \\
\hline ETBE & 0,23 \\
\hline Ethanol & 0,8 \\
\hline TAME & 1,6 \\
\hline IBR & 36,6 \\
\hline RON South Africa & 93,5 \\
\hline Total aromatics & 38,8 \\
\hline Benzene & 0,59 \\
\hline Total oxygen & 1,4 \\
\hline Total olefines & 15,2 \\
\hline MON & 76,6 \\
\hline IBP & 36,8 \\
\hline T 10 & 45,3 \\
\hline T 50 & 104,5 \\
\hline Т 90 & 174,3 \\
\hline
\end{tabular}

Cetane numbers as well as other characteristics of diesel fuel before and after irradiation were determined by Zeltex ZX-440 XL apparatus and are shown in Table 4 and Table 5.

Table 4. Analysis data of diesel fuel before irradiation were determined by Zeltex $Z X-440 X L$.

\begin{tabular}{lc}
\hline Analysis data of of diesel fuel before irradiation were determined by Zeltex $\mathbf{Z X - 4 4 0 ~ X L}$. Temperature $\mathbf{2 0} \mathbf{0}^{\circ} \mathbf{C}$ \\
\hline Density $15^{\circ} \mathrm{C}$ & $851,22 \mathrm{~kg} / \mathrm{m} 3$ \\
Fame ASTM & $0,7 \%$ \\
Cetane number & 49,9 \\
Cetane index & 54,8 \\
PNA & 9 \\
Total aromatics & 0 \\
\hline
\end{tabular}




\begin{tabular}{lc}
\hline Analysis data of of diesel fuel before irradiation were determined by Zeltex $\mathbf{Z X - 4 4 0 ~ X L . ~}$ Temperature $20^{\circ} \mathrm{C}$ \\
\hline IBP & 36,8 \\
T 90 & 343 \\
\hline
\end{tabular}

Table 5. Analysis data of diesel fuel after gamma radiation on $Z X-440$ apparatus XL. Absorbed dose $D=64 \mathrm{kGy}$.

\begin{tabular}{lc}
\hline Analysis data of diesel fuel after gamma radiation on $\mathbf{Z X - 4 4 0}$ apparatus $\mathbf{X L}$. Absorbed dose $\mathbf{D}=\mathbf{6 4} \mathbf{~ k G y}$. Temperature $\mathbf{2 0}^{\circ} \mathbf{C}$ \\
\hline Density $15^{\circ} \mathrm{C}$ & $851,22 \mathrm{~kg} / \mathrm{m} 3$ \\
Fame ASTM & $0,7 \%$ \\
Cetane number & 50,3 \\
Cetane index & 54 \\
PNA & 9 \\
Total aromatics & 0 \\
PNA & 8,9 \\
T 90 & 342 \\
\hline
\end{tabular}

\section{Discussion}

As a result of the influence of $\gamma$-radiation, high-energy fast electrons that can change the chemical properties of molecules are formed in the irradiated medium, chemical bonds are broken, radicals and polymers are formed. In gaseous hydrocarbons, several types of ion-molecular reactions occur: transfer of proton, hydrogen atoms and hydride ion; reactions associated with the rupture and formation of new C-C bonds; reaction of $\mathrm{H}_{2}$ transfer. These are exothermic reactions that do not require activation energy and occur during each collision of ions with molecules [15]. As a result of irradiation, gaseous products increase the amount of unsaturated hydrocarbons. When studying the effect of ionizing radiation on organic materials, two periodsimmediately after irradiation and post-radiation effect are isolated. Changes occurring at the time of irradiation may be reversible or irreversible. Reversible effects depend on dose rate. Irreversible changes in material properties depend on the absorbed dose, temperature, and persist after irradiation, causing chemical transformations of molecules.

Density indirectly characterizes chemical fuel content, fractional composition and vaporability. Increasing the density of gasoline in radiation affects the performance of exhaust gases. One important characteristic of the fuel is viscosity. If the viscosity is above or below the specified limits, the operation of the fuel supply equipment will be disrupted, after which the mixture formation and combustion of the fuel will be disrupted. The viscosity changes the greater the viscosity of the starting material and the greater the absorbed radiation dose. Under the action of radiation there is simultaneous structuring of organic substances - cross-linking of linear molecules or polymerization leading to increase of molecular weight, and their cleavage accompanied by decrease of molecular weight. To some extent, cleavage always occurs because all organic substances at radiolysis to release gas.

Presence of unsaturated hydrocarbons in fuel, as well as such easily oxidizing compounds as mercaptans, determines the chemical stability of fuels during long-term storage. When storing such fuels, the content of actual gums in them increases, the content of mercaptans decreases, and sediments are formed. In recent years, there has been an increased interest in the oxidation and stabilization of jet fuels.

\section{Conclusions}

The processes that have occurred in connection with radiolysis can develop for a long time after the radiation is stopped, which leads to a change in the composition of the fuel. As a result, at ambient temperature, the performance of the fuel is deteriorated. Under the conditions of our experiments, when irradiating gasoline at dose rate $\mathrm{P}=0.18$ $\mathrm{Gy} / \mathrm{s}$ of gamma source $\mathrm{Co}^{60}$ at room temperature and various absorbed doses $\mathrm{D}=15-150 \mathrm{kGy}$, all main characteristics density, viscosity- are deteriorated. As can be seen in Figures 1 and 2, as the absorbed dose and irradiation time increase, the viscosity and density of the fuels increase. Petrol containing a large number of unsaturated hydrocarbons in fuels slightly increases coking ability and deteriorates color during storage. It is necessary to select a composition of petroleum fuels that, even at elevated temperatures, will be better able to withstand the effect of radioactive irradiation by changing the hydrocarbon composition of petroleum products due to minor changes in composition and the introduction of additives. This is due to the tightening of the requirements for the operation characteristics of fuels with the increase in the thermal stress of aircraft engines.

\section{References}

[1] L. Y. Jabbarova. «Radiolysis of motor fuels»./«High Energy Chemistry», M. 2019, V. 53, № 6, p. 471-477.

[2] L. Y. Jabbarova, I. Mustafayev. «High-temperature radiolysis of diesel fuel»/Journal of Applied Spectroscopy, Vol. 85, No. 4, 2018, Springer Science, LLC p. 686-690.

[3] L. Y. Jabbarova, I. I. Mustafayev, R. J. Akberov, S. Z. Melikova, T. N. Akhmedova. «Study of radiolysis of hexanehexene hydrocarbon mixture»/"International Journal of Applied and Fundamental Research", SIC "Academy of Natural History", Moscow 2019, № 9 p. 101-107.

[4] L. Y. Jabbarova. «Study of the effects of ionizing radiation on the hydrocarbon composition of AI -95 and AI -92 gasoline». /International Journal of Applied and Fundamental Research, NIC Academy of Natural Science, "M., 2019 № 4 p. 72-75. 
[5] L. Jabbarova, I. Mustafayev. «Researches of Impact of Ionizing Radiation on Some Characteristics of Diesel Fuel.»/ J. of Energy, Environmental \& Chemical Engineering. USA, V. 2, Issue 4, 2017, pp. 41-45.

[6] L. Y. Jabbarova, I. I. Mustafayev, S. Z. Malikova. "Influence of radiation on petroleum fuels". /"International Journal of Applied and Fundamental Research", SIC "Academy of Natural History", Moscow, No. 7 (Part 2) 2017, p. 239-243.

[7] L. Y. Jabbarova, I. Mustafayev. "Influence of a Radiation on Technical and Operational Qualities of Petrol". /Journal of Energy, Environmental \& Chemical Engineering. USA. Vol. 2, No. 4, 2017, p. 62-66.

[8] L. Y. Jabbarova. S. Z. Melikova, S. M. Aliev. Hightemperature radiolysis of motor gasoline AI-92./ Journal of Radiation Research. 2017 v. 4 №2 s. 47-54.

[9] L. Y. Jabbarova. «Influence of radiation on quality of motor fuels.» /. Azerbaijan University of Architecture and Construction. International scientific-technical Conference. NATURAL DISASTERS AND HUMAN LIFE SAFETY. desember 04-06, 2017 Baku, Azerbaijan. p. 317.

[10] L. Y. Jabbarova. Researches of a high-temperature radiolysis of diesel fuel./Proceedings of International Scientific Conference on Sustainable Development Goals. 24-25 November 2017, Baku, Azerbaijan. pp. 152-155.
[11] L. Y. Jabbarova. S. Z. Melikova, S. M. Aliev. The impact of ionizig Radiation on Diezel fuel./Journal of Radiation Research. Volum 2,№ 2, Baku, Azerbaijan, 2015, p. 71-76.

[12] L. Y. Jabbarova., I. I. Mustafaev, Z. O. Nabizade, R. S. Rzayev S. F. Akhmadbayova. "Radiation Chemical Conversion of Oil Derived from Oil-Bitumen Rock."/Chemistry Journal of Moldova. General, Industrial and Ecological Chemistry. 2014, 9 (1), p. 80-84.

[13] L. Y. Jabbarova, I. I. Mustafayev, S. F. Akhmadbayova, Z. O. NabizadeR. S. Rzayev. Radiation Chemical Conversion of Oil Derived from Oil-Bitumen Rock. Academy of Sciences of Moldova Institute of Chemistry. The Chemical Society of the Republic of Moldova. The International Conference dedicated to the 55th anniversary from the foundation of the Institute of Chemistry of the Academy of Sciences of MOLDOVA. May 28-30, 2014 Chisinau, p. 80-84.

[14] I. I. Mustafayev, L. Y. Jabbarova, Z. O. Nabizadeh, N. E. Ibadov and others. "Investigation of the radiation-chemical transformation of synthetic oil from petroleum bituminous rock". M. "High Energy Chemistry". -2013. No. 6. T. 47. p. $449-455$.

[15] V. K. Milinchuk and others. Radiation resistance of organic materials / Moscow: Energoatomizdat - 1986. p. 272. 